\title{
Spatial risk profiling of Schistosoma japonicum in Eryuan county, Yunnan province, China
}

Peter Steinmann ${ }^{1}$, Xiao-Nong Zhou ${ }^{2}$, Barbara Matthys ${ }^{1}$, Yuan-Lin Li ${ }^{3}$, Hong-Jun Li ${ }^{4}$, Shao-Rong Chen ${ }^{3}$, Zhong Yang', Weng Fan ${ }^{3}$, Tie-Wu Jia ${ }^{2}$, Lan-Hua $\mathrm{Li}^{2}$, Penelope Vounatsou ${ }^{1}$, Jürg Utzinger ${ }^{1}$

${ }^{1}$ Department of Public Health and Epidemiology, Swiss Tropical Institute, P.O. Box, CH-4002 Basel, Switzerland; ${ }^{2}$ National Institute of Parasitic Diseases, Chinese Center for Disease Control and Prevention, Shanghai 200025, People's Republic of China; ${ }^{3}$ Institute of Research and Control of Schistosomiasis in Dali Prefecture, Dali Xiaguan 671000, People's Republic of China; ${ }^{4}$ Eryuan County Schistosomiasis Control Station, Eryuan 671200, People's Republic of China

\begin{abstract}
Bayesian spatial risk profiling holds promise to enhance our understanding of the epidemiology of parasitic diseases, and to target interventions in a cost-effective manner. Here, we present findings from a study using Bayesian variogram models to map and predict the seroprevalence of Schistosoma japonicum in Eryuan county, Yunnan province, China, including risk factor analysis. Questionnaire and serological data were obtained through a cross-sectional survey carried out in 35 randomly selected villages with 3,220 people enrolled. Remotely-sensed environmental data were derived from publicly available databases. Bivariate and non-spatial Bayesian multiple logistic regression models were used to identify associations between the local seroprevalence and demographic (i.e. age and sex), environmental (i.e. location of village, altitude, slope, land surface temperature and normalized difference vegetation index) and socio-economic factors. In the spatially-explicit Bayesian model, S. japonicum seroprevalence was significantly associated with sex, age and the location of the village. Males, those aged below 10 years and inhabitants of villages situated on steep slopes (inclination $\geq 20^{\circ}$ ) or on less precipitous slopes of $>5^{\circ}$ above $2,150 \mathrm{~m}$ were at lower risk of seroconversion than their respective counterparts. Our final prediction model revealed an elevated risk for seroconversion in the plains of the eastern parts of Eryuan county. In conclusion, the prediction map can be utilized for spatial targeting of schistosomiasis control interventions in Eryuan county. Moreover, S. japonicum seroprevalence studies might offer a convenient means to assess the infection pressure experienced by local communities, and to improve risk profiling in areas where the prevalence and infection intensities have come down following repeated rounds of praziquantel administration.
\end{abstract}

Keywords: Schistosoma japonicum, seroprevalence, risk mapping and prediction, Bayesian variogram models, geographical information system, remote sensing, China.

\section{Introduction}

Schistosoma japonicum is a blood-dwelling fluke that is plaguing humans and over 40 domestic and wild animal species in China, Indonesia and the

Corresponding author:

Jürg Utzinger

Department of Public Health and Epidemiology

Swiss Tropical Institute, P.O. Box, CH-4002 Basel, Switzerland

Tel. +4161284 8129; Fax +41612848105

E-mail: juerg.utzinger@unibas.ch
Philippines. Adult female S. japonicum flukes produce eggs, about half of which are trapped in host tissues where they elicit inflammatory immune reactions and organ damage. The remaining eggs are released to the environment via the faeces. Miracidia hatch upon contact of the eggs with freshwater and infect amphibious intermediate host snails of the genus Oncomelania. The emerging cercariae close the transmission cycle by percutaneously penetrating mammalian end hosts during water contact (Ross et al., 2001; Gryseels et al., 2006). In 
China, it is currently estimated that between 700,000 and 850,000 individuals are infected with $S$. japonicum, among the 40 million people at risk of contracting the disease (Zhou et al., 2005). Since the mid-1950s, the Chinese government is implementing a multitude of control measures, including environmental management targeted against the intermediate host snail for transmission containment and mass drug administration for morbidity control (Utzinger et al., 2005). Achievements made to date hold promise for ultimately attaining the final aim of transmission interruption and elimination of schistosomiasis from China (Zhou et al., 2005).

Remote sensing (RS) and geographical information system (GIS) techniques are increasingly used in public health and veterinary sciences (Hay, 2000; Rinaldi et al., 2006), and have given new impetus to the study of infectious diseases (Rogers and Randolph, 2003; Brooker et al., 2006). Their capacity to acquire and process large amounts of spatially-explicit data offers new prospects for the assessment of environmental factors that influence the epidemiology of neglected tropical diseases, including schistosomiasis (Bergquist, 2001; Brooker, 2002; Brooker and Utzinger, 2007). In China, GIS and RS have been widely and effectively utilized for the study and control of $S$. japonicum (Yang et al., 2005c). Yet, the application of GIS and RS has primarily focussed on the mapping of human infections and Oncomelania hupensis habitats at different scales, the prediction of suitable snail habitats in eastern China, and the assessment of the potential impact of environmental transformations and climate change (Yang et al., 2005c; Zhou et al., 2007).

Recently, the integration of a diversity of datasets for risk profiling of malaria and neglected tropical diseases has been advanced by the development of spatial statistical methods, e.g. Bayesian methods and Markov chain Monte Carlo (MCMC) inference (Basáñez et al., 2004; Gemperli et al., 2004). Subsequently, application of these techniques have been successfully extended for risk profiling of schistosomiasis in different African settings (Raso et al., 2005a; Clements et al., 2006). Studies in the mountainous region of Man in western Côte d'Ivoire, for example, suggested that the risk of infection with $S$. mansoni at non-sampled locations could be predicted by demographic, ecological and socio-economic data obtained from questionnaires and satellite-derived environmental data (Raso et al., 2005a; Beck-Wörner et al., 2007).

The objectives of this study were:

(i) to develop a spatially-explicit statistical model by integrating epidemiological and remotelysensed environmental data for risk profiling of $S$. japonicum seroconversion and infection in a mountainous area in China; and

(ii) to explore the potential of serological data for the appreciation of the infection pressure in this setting, where praziquantel has been repeatedly administered over the past several years.

\section{Materials and methods}

\section{Study area}

Our study was carried out in Eryuan, a mountainous county in the northwest of Yunnan province, China. Eryuan county covers an area of approximately $3,000 \mathrm{~km}^{2}$, stretching from $25.80^{\circ}$ to $26.43^{\circ} \mathrm{N}$ latitude and from $99.54^{\circ}$ to $100.43^{\circ} \mathrm{E}$ longitude. Rains mainly occur during the summer monsoon period (June-September). The elevation of the mountainous and partially forested western part of the county is between $1,700 \mathrm{~m}$ and $3,000 \mathrm{~m}$ above sea level. The eastern part features fertile, mountainframed plains at altitudes of 1,950-2,150 m. The autochthonous Bai and the immigrated Han ethnic groups are both engaged in agriculture and animal husbandry. The latter primarily live in the eastern plains. Whilst intensive irrigated farming dominates in plain areas and on terraced mountain slopes, rain-fed agriculture and livestock breeding dominate elsewhere. Infrastructure development started in the plains and is progressing into the mountainous areas. 
Cross-sectional parasitological and questionnaire surveys

The epidemiological data were derived from a cross-sectional community-based survey described in detail elsewhere (Steinmann et al., 2007). In brief, the study included 35 villages that were identified by randomly selecting cells of a $3.5 \times 3.5 \mathrm{~km}$-grid laid over a map of Eryuan county. In every village, 35 families were randomly selected from available community registries. Families were visited in November and December 2005 and the purpose and procedures of the study were explained. In case no adult family member was around during our first encounter, a neighbouring family was invited to participate. All family members aged $\geq 5$ years were enrolled.

The following field procedures were employed. Firstly, individual and family-level risk factors were obtained by means of pre-tested questionnaires. The individual questionnaire recorded demographic features and health-related behaviour. Study participants $<15$ years of age were usually assisted by their parents/legal guardians in answering the questions. The household questionnaire was addressed to the head of the family and assessed general living conditions, and ownership of household assets, livestock and farmland. Secondly, a venous blood sample was collected from each participant, centrifuged on the spot and forwarded to the research station where it was frozen, pending analysis. Thirdly, labelled plastic bags for the collection of stool specimens were handed out to all participants. One stool sample was obtained per individual and forwarded to the schistosomiasis control station at the day of collection.

Finally, the geographical coordinates of participating households were recorded, using a hand-held global positioning system (GPS) receiver (Garmin Ltd., Olathe, USA). The sustained schistosomiasis control and surveillance activities in China have resulted in the classification of all villages into different endemicity levels, taking into account historical and contemporary results from parasitological surveys. Hence, the study villages were classified into schistosome-endemic and non-endemic settle- ments on the basis of this prior knowledge.

In the laboratory, stool samples were first screened for helminth eggs by reading four $42 \mathrm{mg}$ Kato-Katz thick smears per sample under a light microscope (Katz et al., 1972). Eggs were counted and recorded separately for each helminth species. For quality control, $5 \%$ of the slides were re-examined by the senior laboratory technician. A commercially-available enzyme-linked immunosorbent assay (ELISA) was used to test the serum samples for IgG antibodies against S. japonicum (Shenzhen Combined Biotech Co. Ltd., Shenzhen, China). This ELISA test exhibits high sensitivity and specificity and has been extensively used in the national schistosomiasis control programme of China (Zhu, 2005). The standardized positive and negative control sera included in the test kit were employed and the cut-off values specified in the manual were applied for the discrimination between seropositive and seronegative individuals. Cysticerci and Trichinella spp. were also tested for by ELISA (Hai Tai Co. Ltd., Zhuhai, China) according to the manufacturer's instructions.

\section{Demographic and socio-economic data}

The demographic data (i.e. age and sex) were derived from the individual questionnaire. The socio-economic data were extracted from the household questionnaire. We utilized an asset-based approach to stratify the participating families into wealth quintiles. This approach, initially developed in India (Filmer and Pritchett, 2001), and then successfully applied in rural and urban areas of East and West Africa (Armstrong Schellenberg et al., 2003; Raso et al., 2005b; Matthys et al., 2006, 2007), was further adapted to the current setting in rural China.

\section{Environmental data}

Eight-day composite night-time land surface temperature (LST) and 16-day composite normal difference vegetation index (NDVI) data at a nominal re- 
solution of $1 \times 1 \mathrm{~km}$ were obtained for the periods 1 December 2004 to 28 February 2005 and from 1 March 2005 to 31 May 2005, respectively. These data were obtained from the Moderate Resolution Imaging Spectroradiometer (MODIS), made available through the Land Processes Distributed Active Archive Center, U.S. Geological Survey (USGS) (http://edcdaac.usgs.gov/dataproducts.asp). Individual scenes were mosaicked, if necessary, and the required bands re-projected utilizing the appropriate functions of the re-projection tool of MODIS (version 3.3). Scenes were resized in ENVI 4.0 (Research Systems, Inc., Boulder, USA) and values extracted for village centroids and all other pixels. Subsequently, median values over the considered periods were computed. A $90 \mathrm{~m}$ high-resolution Shuttle Radar Topography Mission (SRTM)-derived digital elevation model (DEM) was downloaded from the USGS EROS data center (http:// eros.usgs.gov/). Slopes (in degrees $\left[{ }^{\circ}\right]$ ) were calculated for pixels with similar spatial extent than the LST and NDVI data, using ArcMap version 9.1 (Environmental Systems Research Institute Inc., Redlands, USA) and elevation and slope data were extracted as outlined above. It is known that the intermediate host snail of $S$. japonicum mainly lives in irrigation canals in Eryuan county. In addition, preceding analyses indicated that most $S$. japonicum infections occurred at an elevation below 2,150 m (Steinmann et al., 2007). Therefore, an attempt was made to classify the environment into plain regions $\left(\right.$ slope $<5^{\circ}$ ) and sloped areas below or above 2,150 m. The underlying assumption was that irrigation is more common in plain areas when compared to mountain slopes. However, there are terraced areas in Eryuan county but usually not on steep mountain slopes. For visualizing purposes, all spatial data were displayed in ArcMap version 9.1.

\section{Data management and statistical analysis}

EpiData version 3.1 (EpiData Association, Odense, Denmark) was used for double entry and validation of the questionnaire data. Statistical analysis, including bivariate and multiple logistic regression analyses, were performed in STATA version 9.2 (StataCorp LP, College Station, USA). Potential risk factors for seropositivity were subjected to bivariate logistic regression analysis done for all villages, and for schistosome-endemic and nonendemic villages separately. Demographic, socioeconomic and environmental risk factors which proved to be significant for the full dataset, but were not obviously correlated with each other, were included in the Bayesian non-spatial and spatial multiple logistic regression models.

The infection status $Z_{i j k}$ of individual $k$ within household $j$ at village $i$ was assumed to follow a Bernoulli distribution $\left(Z_{i j k} \sim \operatorname{Ber}\left(p_{i j k}\right)\right)$, whereas $p_{i j k}$ is a measure for the risk of seropositivity for individual $k$ within household $j$ in village $i$. Multiple logistic regression models were fitted with exchangeable random effects $\left(u_{j}, j=1,2,3, \ldots J\right)$ at the household level and spatially correlated random effects $\left(\varphi_{i}, i=1,2,3, \ldots N\right)$ at the village level. Covariates and random effects were modelled on the $\log i t$ scale, that is $\log i t\left(p_{i j k}\right)=X_{i j k} \beta^{T}+u_{j}+\varphi_{i}$. It is assumed that $u_{j} \sim N\left(0, \sigma_{1}^{2}\right), j=1, \ldots J$ and $\varphi \sim \operatorname{MVN}(0, \Sigma)$, where $\sigma_{1}^{2}$ is the between-household variation. $\Sigma_{i j}=\sigma_{2}^{2}$ and $\mathrm{R}\left(d_{i j}, \rho\right)=\exp \left(-\rho d_{i j}\right), \sigma_{2}^{2}$ is the spatial variation, $d_{i j}$ the shortest straight-line distance between village $i_{1}$ and $i_{2}$, and $\rho$ is the rate of how correlation decreases with distance. We assumed an exponential spatial correlation, i.e. $\exp \left(-\rho d_{i j}\right)$. The minimum distance in meters $(\mathrm{m})$ at which spatial correlation between village locations drops below $5 \%$, is known as the range of geographical dependency, which is expressed by $\delta=3 / \rho$.

We chose Normal prior distributions with a mean equal to 0 and a variance equal to 100 for the regression coefficients, inverse gamma prior distributions for $\rho, \sigma_{1}^{2}$ and $\sigma_{2}^{2}$, and gamma prior distribution for $\rho$. A sensitivity analysis for $\rho$ considering informative and non-informative prior distributions has been undertaken. The best fitting model, based on the smallest Bayesian deviance information criterion (DIC) used as a goodness of fit measure, with an informative gamma distribution (mean equal to 1 
and variance equal to 1 ) for $\rho$, has been selected and used for spatial prediction (Spiegelhalter et al., 2002). The model with the smallest DIC was considered as the best fitting one and results will be presented for this model. The model parameters were estimated employing MCMC simulation (Gelfand and Smith, 1990). A single chain sampler with a burn-in of 10,000 iterations was run. The ergodic averages of the model parameters were examined for convergence.

\section{Ethical considerations and anthelmintic treatment}

The institutional review boards of the Swiss Tropical Institute (Basel, Switzerland) and the National Institute of Parasitic Diseases, Chinese Center for Disease Control and Prevention (Shanghai, China) granted approval for this study. The local authorities were informed about the objectives and procedures of the investigation. Written informed consent was obtained from the heads of the participating families.

At the end of the study, a single $40 \mathrm{mg} / \mathrm{kg}$ oral dose of praziquantel was given to individuals with a S. japonicum infection, and a single $400 \mathrm{mg}$ oral dose of albendazole was administered to those with a soil-transmitted helminth infection. Taenia spp. infections were treated with a single dose of $600 \mathrm{mg}$ praziquantel for adults and $400 \mathrm{mg}$ for children. All drugs were administered free of charge.

\section{Results}

\section{Study cohort}

Complete questionnaire, parasitological and serological data were obtained from 3,220 individuals from 1,154 families, which formed our final study cohort. There were 1,793 females $(55.7 \%)$ and the age ranged between 5 and 81 years. The age structure was as follows: $5-9$ years $(8.6 \%), 10-14$ years $(7.7 \%), 15-24$ years $(12.9 \%), 25-39$ years $(35.0 \%)$ and $\geq 40$ years $(35.8 \%)$. Four-fifth of the participants belonged to the Bai minority, and the remain- ing 20\% were Han Chinese. The large majority of the study population were farmers $(80 \%)$, whereas $16 \%$ were students. Animal ownership was almost universal, particularly pigs (reported by $78 \%$ of the families).

With regard to the socio-economic status of the participating families, our household-based asset approach revealed significant spatial heterogeneities in the composition of the village population. The proportion of low socio-economic classes in the villages increased with the distance from the eastern plain, with $99.7 \%$ of the least poor families living at an elevation below 2,150 m.

\section{Parasitological findings}

Parasitological data and risk factors for infection and seroconversion, as assessed by bivariate and multiple logistic regression analyses, have been presented elsewhere (Steinmann et al., 2007). In brief, eggs of five different helminth species were observed, namely Ascaris lumbricoides (15.4\%), Taenia spp. (3.5\%), Trichuris trichiura $(1.7 \%)$, S. japonicum $(1.3 \%)$ and hookworms $(0.3 \%)$. In the 13 known schistosome-endemic villages, the prevalence of $S$. japonicum was $2.7 \%$. Interestingly, four $S$. japonicum infections were discovered in villages that were considered as non-endemic. The seroprevalence of Trichinella spp. and cysticerci-specific antibodies was $58.8 \%$ and $18.5 \%$, respectively. Prominent risk factors for a S. japonicum infection in endemic villages included ethnicity (i.e. Han Chinese), growing tobacco and residency in plain areas and at an elevation $<2,150 \mathrm{~m}$.

\section{Risk factors for S. japonicum seropositivity}

The location and schistosomiasis seroprevalence of each village is displayed in Figure 1 and the key findings regarding the $S$. japonicum seropositives are summarized in Table 1 . The mean seroprevalence of $S$. japonicum in the entire study area was $27.1 \%$. It varied between $16.9 \%$ and $84.8 \%$ (mean $=49.5 \%)$ in known schistosome-endemic and 


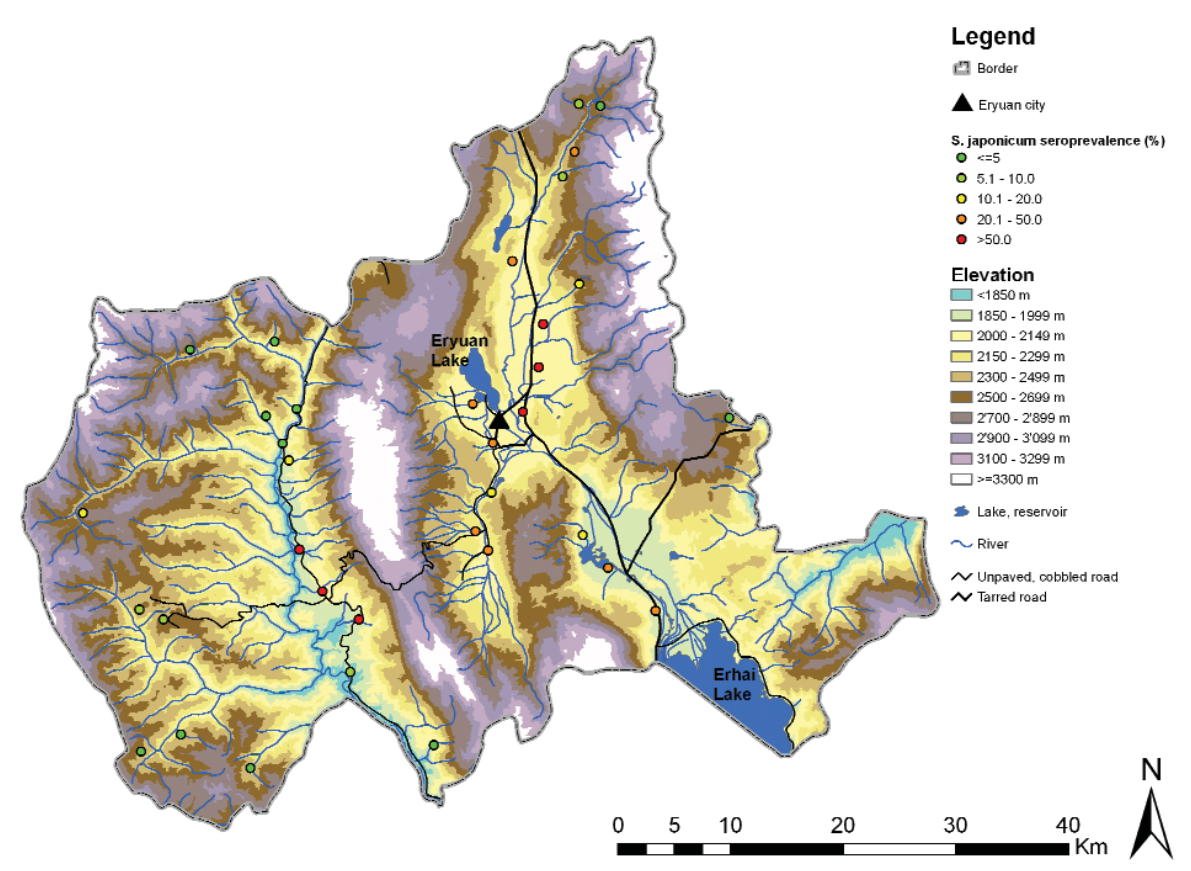

Fig. 1. Measured S. japonicum seroprevalence in 35 study villages in Eryuan county, Yunnan province, China. Also depicted on the map are the elevation, water bodies and roads.

between $1.2 \%$ and $32.1 \%$ (mean $=9.2 \%$ ) in nonendemic villages. Risk factors for seroconversion among residents of non-endemic villages included age ( $\geq 25$ years), socio-economic status (less poor: odds ratio $(\mathrm{OR})=1.95,95 \%$ confidence interval $(\mathrm{CI})=1.17-3.25$; least poor: $\mathrm{OR}=2.10,95 \% \mathrm{CI}=$ 1.21-3.65) and lease of irrigated land with a surface exceeding 1.5 mǔ $\left(1 \mathrm{mǔ}=666.7 \mathrm{~m}^{2}\right)$. Residency at an altitude $\geq 2,150 \mathrm{~m}(\mathrm{OR}=0.55,95 \% \mathrm{CI}=0.40$ 0.76 ) and living on slopes $>5^{\circ}$ was protective (altitudes $<2,150 \mathrm{~m}: \mathrm{OR}=0.59,95 \% \mathrm{CI}=0.36-0.95$; altitude $\geq 2,150 \mathrm{~m}$ : $\mathrm{OR}=0.38,95 \% \mathrm{CI}=0.25$ 0.60). A higher socio-economic status and residency in a plain area were strong risk factor for seroconversion in the entire study population but the former was protective in known schistosome-endemic areas. The median night-time LST between December 2004 and February 2005 was a predictor for seropositivity in Eryuan county, whereas the median NDVI between March and May 2005 was negatively correlated with seropositivity.

\section{Risk mapping and prediction}

The non-spatial multiple logistic regression model for all surveyed villages included significant demographic, socio-economic and environmental covariates identified in the bivariate logistic regression analysis. Key findings derived from the models are summarised in Table 2 . In the bivariate analysis, there were significant associations between the serostatus and age, sex, socio-economic status, village location, the median night-time LST between December 2004 and February 2005 and the median NDVI between March and May 2005. Females and individuals aged $\geq 10$ years, compared to the youngest age group (5-10 years), were at a higher risk of seroconversion. On the other hand, a higher socio-economic status was a protective factor. Tobacco growing and working irrigated farmland was a risk factor for seropositivity. Inhabitants of villages located on slopes with an inclination $>5^{\circ}$ and at an altitude above $2,150 \mathrm{~m}$, as well as those in 
Table 1. Bivariate logistic regression analyses of the relationship between the S. japonicum serostatus and demographic indicators, socio-economic status of the families, village location and environmental covariates in Eryuan county, Yunnan province, China, stratified by known endemicity of $S$. japonicum at the village level.

\begin{tabular}{|c|c|c|c|c|c|c|}
\hline \multirow{4}{*}{$\begin{array}{l}\text { Prevalence (\%) at village level (range) } \\
\text { Risk factors }\end{array}$} & \multicolumn{6}{|c|}{ S. japonicum seropositivity (based on ELISA results) } \\
\hline & \multicolumn{2}{|l|}{ All villages } & \multicolumn{2}{|c|}{ Schistosome-endemic villages } & \multicolumn{2}{|c|}{ Non-endemic villages } \\
\hline & \multicolumn{2}{|c|}{$27.1(1.2-84.8)$} & \multicolumn{2}{|c|}{$49.5(16.9-84.8)$} & \multicolumn{2}{|c|}{$9.2(1.2-32.1)$} \\
\hline & OR $(95 \% \mathrm{CI})$ & p-value & OR $(95 \% \mathrm{CI})$ & p-value & OR $(95 \% \mathrm{CI})$ & p-value \\
\hline \multicolumn{7}{|l|}{ Sex } \\
\hline Female & 1.00 & & 1.00 & & 1.00 & \\
\hline Male & $0.79(0.67-0.92)$ & 0.003 & $0.72(0.58-0.89)$ & 0.002 & $0.76(0.55-1.06)$ & 0.108 \\
\hline \multicolumn{7}{|l|}{ Age (years) } \\
\hline $5-9$ & 1.00 & & 1.00 & & 1.00 & \\
\hline $10-14$ & $2.06(1.27-3.34)$ & 0.004 & $2.39(1.35-4.22)$ & 0.003 & $1.46(0.38-5.56)$ & 0.576 \\
\hline $15-24$ & $2.27(1.46-3.52)$ & $<0.001$ & $3.23(1.91-5.48)$ & $<0.001$ & $2.36(0.77-7.24)$ & 0.134 \\
\hline $25-39$ & $3.68(2.48-5.46)$ & $<0.001$ & $4.80(3.02-7.64)$ & $<0.001$ & $4.79(1.72-13.31)$ & 0.003 \\
\hline$\geq 40$ & $3.29(2.22-4.88)$ & $<0.001$ & $3.48(2.20-5.52)$ & $<0.001$ & $4.84(1.74-13.47)$ & 0.003 \\
\hline \multicolumn{7}{|l|}{ Education if age $\geq 18$ years } \\
\hline Illiterate & 1.00 & & 1.00 & & 1.00 & \\
\hline$\leq$ Junior middle school & $2.06(1.69-2.51)$ & $<0.001$ & $1.10(0.81-1.49)$ & 0.533 & $1.31(0.92-1.87)$ & 0.141 \\
\hline$\geq$ High middle school & $1.55(0.99-2.42)$ & 0.053 & $0.65(0.37-1.15)$ & 0.137 & $1.16(0.44-3.04)$ & 0.768 \\
\hline \multicolumn{7}{|l|}{ Ethnic group } \\
\hline $\mathrm{Bai}$ & 1.00 & & 1.00 & & 1.00 & \\
\hline Han & $2.37(1.97-2.84)$ & $<0.001$ & $2.40(1.87-3.07)$ & $<0.001$ & $1.13(0.73-1.75)$ & 0.576 \\
\hline Tobacco grower & $2.03(1.06-2.57)$ & $<0.001$ & $4.32(2.91-6.41)$ & $<0.001$ & $0.59(0.30-1.14)$ & 0.115 \\
\hline Livestock breeder & $1.97(1.68-2.31)$ & $<0.001$ & $1.20(0.97-1.48)$ & 0.090 & $1.08(0.76-1.53)$ & 0.665 \\
\hline Temporary employment & $0.97(0.59-1.60)$ & 0.920 & $1.44(0.63-3.26)$ & 0.383 & $1.57(0.73-3.36)$ & 0.250 \\
\hline \multicolumn{7}{|l|}{ Socio-economic status } \\
\hline Most poor & 1.00 & & 1.00 & & 1.00 & \\
\hline Very poor & $3.47(2.35-5.12)$ & $<0.001$ & n.a. & & $1.51(0.96-2.36)$ & 0.075 \\
\hline Poor & $3.95(2.69-5.79)$ & $<0.001$ & $0.71(0.44-1.14)$ & 0.158 & $0.98(0.59-1.63)$ & 0.949 \\
\hline Less poor & $7.77(5.38-11.22)$ & $<0.001$ & $0.54(0.35-0.82)$ & 0.004 & $1.95(1.17-3.25)$ & 0.011 \\
\hline Least poor & $8.41(5.85-12.10)$ & $<0.001$ & $0.48(0.32-0.73)$ & 0.001 & $2.10(1.21-3.65)$ & 0.008 \\
\hline \multicolumn{7}{|l|}{ Tenancy of irrigated agricultural land } \\
\hline No irrigated land & 1.00 & & 1.00 & & 1.00 & \\
\hline $0.1-1.5 \mathrm{mŭ}^{\mathrm{a}}$ & $3.03(2.19-4.20)$ & $<0.001$ & $0.78(0.53-1.13)$ & 0.188 & $1.37(0.90-2.10)$ & 0.141 \\
\hline $1.6-2.5$ mǔa $^{a}$ & $7.63(5.67-10.28)$ & $<0.001$ & n.a. & & $2.01(1.21-3.35)$ & 0.007 \\
\hline 2.6-3.5 mǔa & $8.94(6.67-12.02)$ & $<0.001$ & $0.98(0.74-1.30)$ & 0.905 & $3.15(1.92-5.18)$ & $<0.001$ \\
\hline$>3.5 \mathrm{mŭ}^{\mathrm{a}}$ & $16.62(12.34-22.39)$ & $<0.001$ & $1.61(1.22-2.12)$ & 0.001 & $3.43(1.59-7.41)$ & 0.002 \\
\hline Resident at altitude $\geq 2,150 \mathrm{~m}$ & $0.13(0.10-0.16)$ & $<0.001$ & n.a. & & $0.55(0.40-0.76)$ & $<0.001$ \\
\hline \multicolumn{7}{|l|}{ Slope } \\
\hline$<10^{\circ}$ & 1.00 & & 1.00 & & 1.00 & \\
\hline 10 to $<20^{\circ}$ & $0.16(0.13-0.20)$ & $<0.001$ & $0.40(0.27-0.57)$ & $<0.001$ & $0.49(0.35-0.69)$ & $<0.001$ \\
\hline$\geq 20^{\circ}$ & $0.10(0.07-0.14)$ & $<0.001$ & $0.16(0.11-0.23)$ & $<0.001$ & $0.13(0.07-0.26)$ & 0.001 \\
\hline \multicolumn{7}{|l|}{ Village location } \\
\hline Plain area $\left(\right.$ slope $\left.\leq 5^{\circ}\right)$ & 1.00 & & 1.00 & & 1.00 & \\
\hline Slope $>5^{\circ}$, altitude $<2,150 \mathrm{~m}$ & $0.47(0.39-0.56)$ & $<0.001$ & $0.57(0.46-0.70)$ & $<0.001$ & $0.59(0.36-0.95)$ & 0.032 \\
\hline Slope $>5^{\circ}$, altitude $\geq 2,150 \mathrm{~m}$ & $0.08(0.06-0.11)$ & $<0.001$ & n.a. & & $0.38(0.25-0.60)$ & $<0.001$ \\
\hline Median night-time LST $^{\mathrm{b}}$ & $1.47(1.39-1.56)$ & $<0.001$ & $1.03(0.94-1.13)$ & 0.561 & $1.10(0.99-1.23)$ & 0.067 \\
\hline Median NDVI ${ }^{c}$ & $0.028(0.02-0.005)$ & $<0.001$ & $1.88(0.80-4.44)$ & 0.149 & $3.22(0.68-15.20)$ & 0.140 \\
\hline
\end{tabular}

$\mathrm{OR}=$ odds ratio; $\mathrm{CI}=$ confidence interval; n.a. $=$ not assessed

a $1 \mathrm{mǔ}=666.7 \mathrm{~m}^{2}$

${ }^{\mathrm{b}}$ LST = land surface temperature; period: December 2004 to February 2005

${ }^{\mathrm{c}} \mathrm{NDVI}=$ normalized difference vegetation index; period: March to May 2005 
Table 2. Non-spatial and spatially-explicit multiple logistic regression model for the analysis of the relationship between the S. japonicum serostatus and demographic indicators, socio-economic status of the families, village location and environmental covariates in the 35 study villages in Eryuan county, Yunnan province, China.

\begin{tabular}{|c|c|c|c|c|}
\hline \multirow[t]{3}{*}{ Risk factors } & \multicolumn{4}{|c|}{ S. japonicum seropositivity (based on ELISA results) } \\
\hline & \multicolumn{2}{|c|}{ Non-spatial model } & \multicolumn{2}{|c|}{ Spatial model } \\
\hline & OR & $(95 \% \mathrm{CI})$ & OR & $(95 \% \mathrm{BCI})$ \\
\hline \multicolumn{5}{|l|}{$\overline{\text { Sex }}$} \\
\hline Female & 1.00 & & 1.00 & \\
\hline Male & 0.75 & $0.62-0.90$ & 0.73 & $0.59-0.88$ \\
\hline \multicolumn{5}{|l|}{ Age (years) } \\
\hline $5-9$ & 1.00 & & 1.00 & \\
\hline $10-14$ & 2.45 & $1.40-4.03$ & 2.56 & $1.37-4.42$ \\
\hline $15-24$ & 3.05 & $1.83-4.85$ & 4.48 & $2.54-7.50$ \\
\hline $25-39$ & 4.69 & $2.99-7.15$ & 7.11 & $4.3-11.39$ \\
\hline$\geq 40$ & 3.70 & $2.37-5.62$ & 5.70 & $3.45-9.11$ \\
\hline \multicolumn{5}{|l|}{ Ethnic group } \\
\hline Bai & 1.00 & & 1.00 & \\
\hline Han & 0.82 & $0.62-1.07$ & 0.82 & $0.50-1.25$ \\
\hline Tobacco grower & 1.91 & $1.34-2.65$ & 1.31 & $0.82-1.97$ \\
\hline \multicolumn{5}{|l|}{ Socio-economic status } \\
\hline Most poor & 1.00 & & 1.00 & \\
\hline Very poor & 0.99 & $0.57-1.59$ & 1.37 & $0.73-2.34$ \\
\hline Poor & 0.69 & $0.39-1.12$ & 1.04 & $0.52-1.86$ \\
\hline Less poor & 0.76 & $0.42-1.26$ & 1.10 & $0.54-2.00$ \\
\hline Least poor & 0.59 & $0.32-0.99$ & 0.79 & $0.38-1.46$ \\
\hline \multicolumn{5}{|l|}{ Tenancy of irrigated agricultural land } \\
\hline No irrigated land & 1.00 & & 1.00 & \\
\hline $0.1-1.5 \mathrm{mŭ}^{\mathrm{a}}$ & 0.97 & $0.54-1.61$ & 0.80 & $0.40-1.42$ \\
\hline 1.6-2.5 múa & 1.56 & $0.85-2.63$ & 0.96 & $0.47-1.75$ \\
\hline $2.6-3.5$ mŭa $^{\mathrm{a}}$ & 1.83 & $1.00-3.08$ & 0.93 & $0.46-1.70$ \\
\hline$>3.5$ múa $^{\mathrm{a}}$ & 3.02 & $1.65-5.13$ & 1.09 & $0.52-2.03$ \\
\hline \multicolumn{5}{|l|}{ Slope } \\
\hline$<10^{\circ}$ & 1.00 & & 1.00 & \\
\hline $10-<20^{\circ}$ & 0.46 & $0.34-0.61$ & 0.58 & $0.11-1.76$ \\
\hline$\geq 20^{\circ}$ & 0.19 & $0.13-0.28$ & 0.25 & $0.04-0.81$ \\
\hline \multicolumn{5}{|l|}{ Village location } \\
\hline Plain area $\left(\right.$ slope $\left.\leq 5^{\circ}\right)$ & 1.00 & & 1.00 & \\
\hline Slope $>5^{\circ}$, altitude $<2,150 \mathrm{~m}$ & 0.91 & $0.69-1.17$ & 0.83 & $0.19-2.26$ \\
\hline Slope $>5^{\circ}$, altitude $\geq 2,150 \mathrm{~m}$ & 0.25 & $0.13-0.43$ & 0.19 & $0.02-0.69$ \\
\hline Median night-time LST $^{\mathrm{b}}$ & 0.98 & $0.93-1.02$ & 0.97 & $0.88-1.04$ \\
\hline Median $\mathrm{NDVI}^{\mathrm{c}}$ & 0.08 & $0.03-0.16$ & 0.25 & $<0.01-1.52$ \\
\hline Sigma (spatial variation) & & & 1.36 & $1.27-2.56$ \\
\hline Sigma1 (non-spatial variation) & & & 0.07 & $0.06-0.15$ \\
\hline Phi (smoothing parameter) & & & 0.00123 & $0.00109-0.00276$ \\
\hline Deviance information criterion (total) & 2967.0 & & 2698.9 & \\
\hline
\end{tabular}

Odds ratios (OR) are shown with $95 \%$ confidence interval (CI) and 95\% Bayesian credible interval (BCI)

a 1 mǔ $=666.7 \mathrm{~m}^{2}$

${ }^{\mathrm{b}}$ LST = land surface temperature; period: December 2004 to February 2005

${ }^{c}$ NDVI = normalized difference vegetation index; period: March to May 2005 


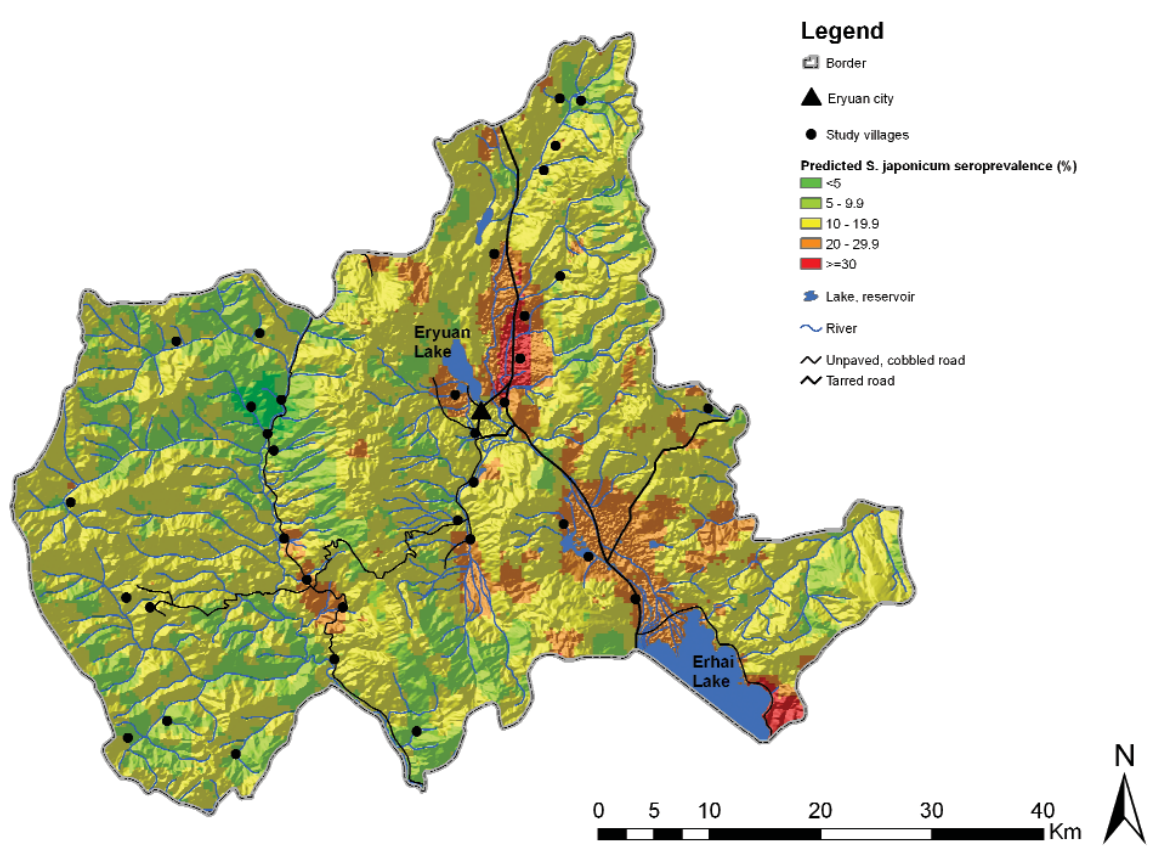

Fig. 2. Map of the predicted S. japonicum seroprevalence in Eryuan county, Yunnan province, China. The prediction is based on the spatially-explicit logistic regression model and the smoothed map was produced by an exponential kriging approach.

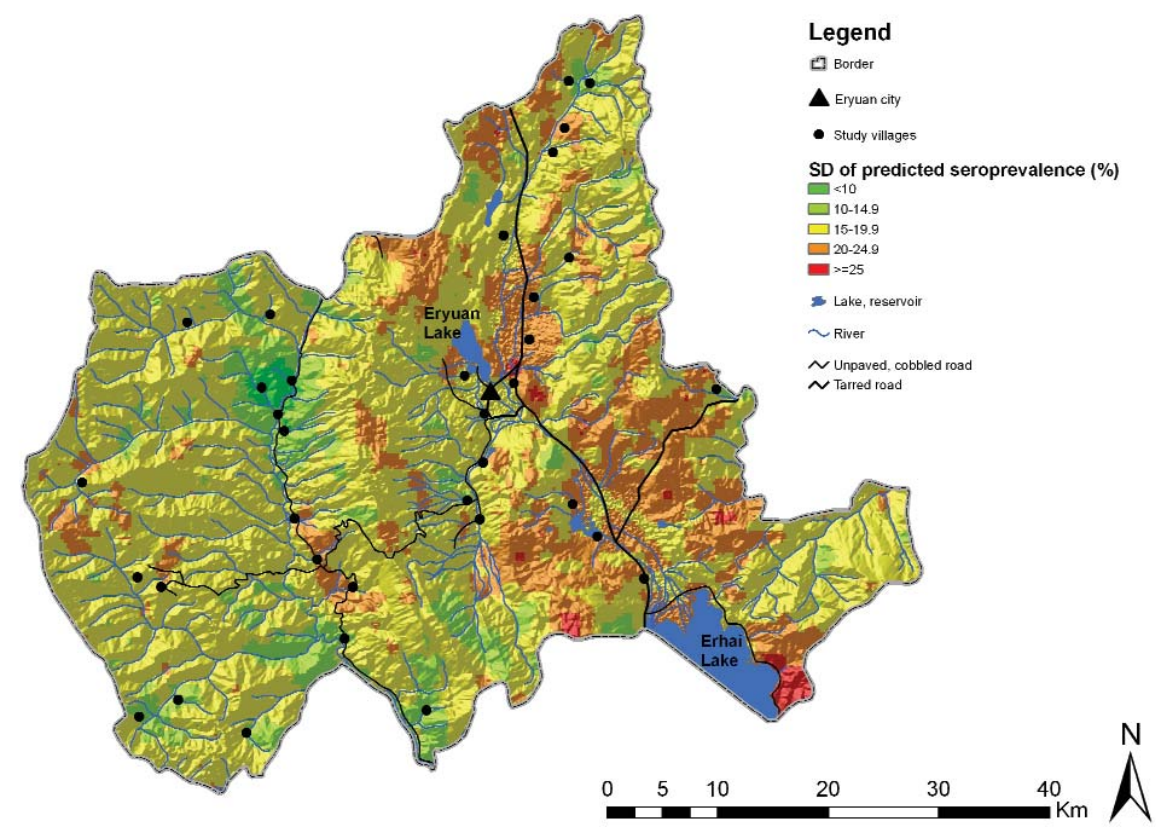

Fig. 3. Map of the standard error of the predicted S. japonicum seroprevalence in Eryuan county, Yunnan province, China. The prediction is based on the spatially-explicit logistic regression model and the smoothed map was produced by an exponential kriging approach. 
villages on mountainsides with an inclination $>10^{\circ}$ at any elevation, were less likely to be seropositive. A higher median NDVI between March and May 2005 at the location of the study villages was protective against seroconversion.

The results of the spatially-explicit logistic regression model, which included the same covariates as those described before, are also shown in Table 2. Whilst sex and age remained significant risk factors for seroconversion, the other covariates showed no statistical significance, with the exception of the village location. In fact, inhabitants of villages situated on steep slopes (inclination $\geq 20^{\circ}$ ) or on a less precipitous slope of $>5^{\circ}$ above $2,150 \mathrm{~m}$ were at a lower risk of seropositivity than people living in plain areas.

The predicted schistosomiasis seroprevalence at non-sampled locations in Eryuan county is displayed in Figure 2. Figure 3 shows the corresponding standard error of the prediction. The highest prevalences are predicted for the plain areas between Erhai Lake and Eryuan Lake, and for the wide valleys in the western part of the county wherever the mountain slopes are not too steep and the elevation is lower than in the eastern plains. Spatial correlation between two locations dropped below $5 \%$ at a distance of $2.5 \mathrm{~km}$.

\section{Discussion}

To our knowledge, this is the first attempt to predict the seroprevalence of $S$. japonicum in a mountainous part of Yunnan province in southwest China. We employed a widely used diagnostic assay, i.e. ELISA (Wu, 2002; Zhu, 2005), and screened 3,220 individuals, aged 5-81 years, randomly selected from 35 villages in Eryuan county. Demographic and socio-economic data, obtained by questionnaires, and remotely-sensed environmental data were utilized for risk factor analysis for seroconversion, and to map and predict the seroprevalence at sampled and non-sampled locations in the study area.

Both the bivariate analysis and the non-spatial model identified various demographic, socio-eco- nomic and environmental risk factors for seroconversion. In the spatial model, however, the only risk factors that remained significant were sex, age, and two covariates describing the village location with regard to slope and altitude. Age, sex and altitude were also identified as risk factors for an infection with $S$. mansoni in a previous study focussing on schoolchildren living in a mountainous area of Côte d'Ivoire (Raso et al., 2005a). In addition, that study reported a strong correlation between infection and the socio-economic status, whereas we did not find such a relationship. The Côte d'Ivoire study found that the environmental covariates, i.e. LST and NDVI, were less important determinants of the local prevalence if spatial correlation was taken into account. On county level and higher administrative units, however, these and other environmental covariates have been identified as important predictors for schistosomiasis japonica (Yang et al., $2005 \mathrm{a}, \mathrm{c})$. The development of a DEM and further spatial analyses of the Côte d'Ivoire data found that proximity to streams with an order 3 (according to a classification proposed by Strahler in the mid1950s) was a good predictor for a $S$. mansoni infection, most likely explained by the distribution of Biomphalaria pfeifferi, the intermediate host snail of intestinal schistosomiasis in Côte d'Ivoire (BeckWörner et al., 2007).

In Eryuan county, O. hupensis is mainly found along irrigation and drainage canals and ponds. Hence, we speculate that humans are predominantly infected during occupational activities in irrigated areas (Huang and Manderson, 2005). The higher seroprevalence among older age groups supports this notion. Indeed, we found that tobacco farmers and those working in large irrigated areas are at higher risk of seropositivity. Irrigated agriculture is mainly performed in the plains or on gently inclined slopes. People living in these areas were at higher risk of seroconversion than those residing on steeper mountain slopes. Interestingly, the plain areas are economically more advanced, and most of the families with higher socio-economic status live in the plains (Steinmann et al., 2007). This observation 
could, at least partly, explain why relative wealth was not protective as it was seen in other settings (Huang and Manderson, 2005; Raso et al., 2005a). The slope and elevation of the village were used as proxies for the location and relief of the fields which are generally located nearby.

Previous research has indicated that the $0-1^{\circ} \mathrm{C}$ January isotherme limits the northern range of O. hupensis in otherwise suitable snail habitats in eastern China (Yang et al., 2005b; Zhou et al., 2007). It remains to be seen if a corresponding critical value can be determined in the schistosomeendemic mountainous areas of western China, where a temperature-dependent limitation at a certain elevation would be expected. We found an inverse relationship between seroprevalence and altitude, but this could also be explained by steeper slopes and, consequently, fewer potentially suitable snail habitats at higher altitudes. We distinguished slopes above and below 2,150 m. This altitude cutoff was motivated by geographical criteria; it represents the upper delimitation of the slightly inclined plain areas in eastern Eryuan, rather than a temperature threshold.

As a whole, a picture emerges where the regional epidemiological situation of schistosomiasis japonica is governed by environmental factors determining the presence or absence of the intermediate host snail, whilst the local prevalence reflects demographic (occupation playing a key role) and socioeconomic risk factors and the influence of sustained control efforts.

There are several shortcomings of our study that warrant discussion. The points offered here might also provide some directions for further research. Firstly, the availability of high-resolution RS data from China is still somewhat limited. For example, we were unable to derive detailed information on different land-use patterns, including irrigated agriculture, and common soil types and moisture. The availability of such environmental data might enhance the predictive power of spatially-explicit models. It is conceivable that the identification of agricultural land utilized by the farmers from each village, and its classification into different crop and irrigation types, as well as the determination of the non-agricultural population and their movements, could aid in further refining S. japonicum risk profiles. Secondly, models for the prediction of snail habitats, including the identification of critical isothermes governing $O$. hupensis populations in mountainous areas, should be developed and results incorporated in the prediction of human infection. The prediction of the snail habitats would also enable the determination of the distance between villages and potential snail habitats, and hence the inclusion of this covariate in future predictive models.

The national schistosomiasis control programme in China has led to the elimination of schistosomiasis japonica from five of the previously 12 endemic provinces and has achieved a significant reduction of the number of cases in the remaining endemic areas (Utzinger et al., 2005; Zhou et al., 2005). Repeated rounds of praziquantel, administered at a large scale, have not only reduced the prevalence of infection, but have also decreased the mean intensity of infection and morbidity, and had an impact on transmission (Guo et al., 2006). At present, most infections are light and, consequently, the widely used Kato-Katz technique has become unreliable to detect all active infections, particularly if only a single stool sample is examined (Yu et al., 1998; Wang et al., 2006). Nevertheless, a recent study concluded that the Kato-Katz technique is still recommended for screening of S. japonicum (Yu et al., 2007). However, more than a decade ago, the low prevalence of $S$. japonicum across large parts of China has led to the adoption of a two-pronged diagnostic approach, namely population screening by a serological assay (e.g. indirect hemagglutination assay or ELISA), followed by microscopic examination of stool samples from seropositive individuals ( $\mathrm{Zhu}$, 2005).

The invasive nature of the screening test and the effort required to screen entire populations call for other means to promptly and reliably identify highrisk populations to target control efforts in a costeffective manner. Snail surveys, including the deter- 
mination of the S. japonicum infection status of recovered $O$. hupensis, is the traditional means to identify schistosome-endemic areas in China (Utzinger et al., 2005) and control efforts are focused on these snail-endemic areas. These surveys are labour intensive as the focal nature of O. hupensis requires a dense network of sampling sites and the snail infection rate is generally low. The development of spatially-explicit prediction models for the identification of potential snail habitats, employing remotely-sensed environmental data holds promise to focus ground surveys on those areas that are ecologically suitable for O. hupensis (Yang et al., 2005c). Prediction models could also help to identify even relatively small habitats that might have been overlooked thus far.

The prediction of the seroprevalence among humans could focus the control activities targeting humans on those areas where they are most needed. The use of serological screening methods in areas of low infection intensity after repeated rounds of chemotherapy has been advocated repeatedly (Maddison, 1987; Hoshino-Shimizu et al., 1992). Indeed, previous experiences from sero-epidemiological studies in areas of low endemicity highlight the advantages associated with the use of serological methods for surveillance, e.g. in the Philippines (Yogore et al., 1983), Kenya (Doenhoff et al., 1993) and Puerto Rico (Hillyer and Soler de Galanes, 1999). The use of the seroprevalence instead of the parasitological prevalence is justified on the following grounds. Firstly, the serostatus offers an idea on the infection pressure irrespective of recent control activities. Most people seroconvert shortly after the infection and about half of them remain seropositive 1-2 years after they have been parasitologically cured (Zhu, 2005). However, it should be noted that serological techniques do not reliably distinguish current from past infections. Secondly, the sensitivity of the Kato-Katz technique employed on a single stool sample is low, especially for light infections (Yu et al., 1998; Wang et al., 2006), and the collection of multiple stool samples from the same person during large-scale surveys is difficult due to logistical and financial constraints. Blood tests, on the other hand, are a standard means in large-scale surveys in China, as they are quick and relatively inexpensive ( $\mathrm{Zhu}$, 2005). Thirdly, an enhanced focus on humans has the advantage that at-risk populations might be identified and included into future control efforts, even if they do not live in the vicinity of snail areas, but are nonetheless at risk of infection at more distant sites. Seropositives or even parasitologically-positive people can be found in areas that are considered nonendemic based on the traditional approach of first screening the local population of areas where infected snails are found by a serological method and subsequently assessing a single stool sample of the seropositives by the Kato-Katz technique. This was also shown in the present study (Steinmann et al., 2007). Fourthly, the continued success of chemotherapy-based morbidity control in China will lead to an ever growing share of low-intensity infections. However, it is unlikely that praziquantel alone will be sufficient to completely and permanently eliminate schistosomiasis from entire regions (Utzinger et al., 2003; Bergquist et al., 2005; King et al., 2006). Working with the serostatus rather than the parasitologically-confirmed infection could offer an alternative to overcome some of these challenges.

We conjecture that the seroprevalence can be regarded as an indicator of the epidemiological situation in the absence of chemotherapy. As long as transmission sites exist and people come into contact with them, there is seroconversion, even if ensuing disease is rare due to individual treatment or mass treatment campaigns. A large difference between the seroprevalence and the parasitological prevalence could indicate a prominence of treatment in the set of employed tools for control. If the difference is maintained, it could further mean that the discontinuation of chemotherapy-based control efforts will ultimately result in an increase of the parasitological prevalence up to the seroprevalence level. It could therefore be argued that the gap between the seroprevalence and the parasitological prevalence is a measure for the effectiveness and sustainability of control. 


\section{Acknowledgements}

We are grateful to the study participants and the staff of the Institute of Research and Control of Schistosomiasis in Dali prefecture and the Eryuan County Schistosomiasis Control Station for their commitment during this study. We acknowledge the great support of the local authorities. This investigation received financial support from the Swiss National Science Foundation (project no. PPOOB-102883), the National Natural Science Foundation of China (no. 30590373) and the UNICEF/UNDP/World Bank/WHO Special Programme for Research and Training in Tropical Diseases (TDR) (no. A30298). Peter Steinmann is supported by the Freiwillige Akademische Gesellschaft, Basel, the Commission for Research Partnerships with Developing Countries (through the SDC-sponsored programme "Jeunes Chercheurs") and receives a personal stipend for the final year of his PhD thesis from the Janggen-Pöhn Stiftung.

\section{References}

Armstrong Schellenberg J, Victora CG, Mushi A, de Savigny D, Schellenberg D, Mshinda H, Bryce J, 2003. Inequities among the very poor: health care for children in rural southern Tanzania. Lancet 361, 561-566.

Basáñez MG, Marshall C, Carabin H, Gyorkos T, Joseph L, 2004. Bayesian statistics for parasitologists. Trends Parasitol 20, 85-91.

Beck-Wörner C, Raso G, Vounatsou P, N'Goran EK, Rigo G, Parlow E, Utzinger J, 2007. Bayesian spatial risk prediction of Schistosoma mansoni infection in western Côte d'Ivoire using a remotely-sensed digital elevation model. Am J Trop Med Hyg 76, 956-963.

Bergquist NR, 2001. Vector-borne parasitic diseases: new trends in data collection and risk assessment. Acta Trop 79, 13-20.

Bergquist NR, Leonardo LR, Mitchell GF, 2005. Vaccinelinked chemotherapy: can schistosomiasis control benefit from an integrated approach? Trends Parasitol 21, 112117.

Brooker S, 2002. Schistosomes, snails and satellites. Acta Trop 82, 207-214.

Brooker S, Clements ACA, Bundy DAP, 2006. Global epidemiology, ecology and control of soil-transmitted helminth infections. Adv Parasitol 62, 221-261.

Brooker S, Utzinger J, 2007. Integrated disease mapping in a polyparasitic world. Geospatial Health 1, 141-146.

Clements ACA, Lwambo NJS, Blair L, Nyandindi U, Kaatano G, Kinung'hi S, Webster JP, Fenwick A, Brooker S, 2006. Bayesian spatial analysis and disease mapping: tools to enhance planning and implementation of a schistosomiasis control programme in Tanzania. Trop Med Int Health $11,490-503$.

Doenhoff MJ, Butterworth AE, Hayes RJ, Sturrock RF, Ouma JH, Koech D, Prentice M, Bain J, 1993. Seroepidemiology and serodiagnosis of schistosomiasis in Kenya using crude and purified egg antigens of Schistosoma mansoni in ELISA. Trans R Soc Trop Med Hyg 87, 42-48.

Filmer D, Pritchett LH, 2001. Estimating wealth effects without expenditure data - or tears: an application to educational enrollments in states of India. Demography 38, 115-132.

Gelfand AE, Smith AFM, 1990. Sampling-based approaches to calculating marginal densities. J Am Stat Assoc 85, 398-409.

Gemperli A, Vounatsou P, Kleinschmidt I, Bagayoko M, Lengeler C, Smith T, 2004. Spatial patterns of infant mortality in Mali: the effect of malaria endemicity. Am J Epidemiol 159, 64-72.

Gryseels B, Polman K, Clerinx J, Kestens L, 2006. Human schistosomiasis. Lancet 368, 1106-1118.

Guo JG, Li YS, Gray D, Ning A, Hu GH, Chen HG, Davis GM, Sleigh A, Feng Z, McManus DP, Williams GM, 2006. A drug-based intervention study on the importance of buffaloes for human Schistosoma japonicum infections around Poyang Lake, People's Republic of China. Am J Trop Med Hyg 74, 335-341.

Hay SI, 2000. An overview of remote sensing and geodesy for epidemiology and public health application. Adv Parasitol 47, 1-35.

Hillyer GV, Soler de Galanes M, 1999. Seroepidemiology of schistosomiasis in Puerto Rico: evidence for vanishing endemicity. Am J Trop Med Hyg 60, 827-830.

Hoshino-Shimizu S, Dias LC, Kanamura HY, Silva LC, Glasser CM, Patucci RMJ, 1992. Seroepidemiology of schistosomiasis mansoni. Mem Inst Oswaldo Cruz 87, 303-306.

Huang YX, Manderson L, 2005. The social and economic 
context and determinants of schistosomiasis japonica. Acta Trop 96, 223-231.

Katz N, Chaves A, Pellegrino J, 1972. A simple device for quantitative stool thick-smear technique in schistosomiasis mansoni. Rev Inst Med Trop São Paulo 14, 397-400.

King CH, Sturrock RF, Kariuki HC, Hamburger J, 2006. Transmission control for schistosomiasis - why it matters now. Trends Parasitol 22, 575-582.

Maddison SE, 1987. The present status of serodiagnosis and seroepidemiology of schistosomiasis. Diagn Microbiol Infect Dis 7, 93-105.

Matthys B, Tschannen AB, Tian-Bi NT, Comoé H, Diabaté S, Traoré M, Vounatsou P, Gosoniu L, Raso G, Tanner M, Cissé G, N'Goran EK, Utzinger J, 2007. Risk factors for Schistosoma mansoni and hookworm infections in a town of western Côte d'Ivoire. Trop Med Int Health 12, 709-723. Matthys B, Vounatsou P, Raso G, Tschannen AB, Becket EG, Gosoniu L, Cissé G, Tanner M, N’Goran EK, Utzinger J, 2006. Urban farming and malaria risk factors in a medium-sized town in Côte d'Ivoire. Am J Trop Med Hyg 75, 1223-1231.

Raso G, Matthys B, N'Goran EK, Tanner M, Vounatsou P, Utzinger J, 2005a. Spatial risk prediction and mapping of Schistosoma mansoni infections among schoolchildren living in western Côte d'Ivoire. Parasitology 131, 97-108.

Raso G, Utzinger J, Silué KD, Ouattara M, Yapi A, Toty A, Matthys B, Vounatsou P, Tanner M, N'Goran EK, 2005b. Disparities in parasitic infections, perceived ill health and access to health care among poorer and less poor schoolchildren of rural Côte d'Ivoire. Trop Med Int Health 10, 42-57.

Rinaldi L, Musella V, Biggeri A, Cringoli G, 2006. New insights into the application of geographical information systems and remote sensing in veterinary parasitology. Geospatial Health 1, 33-47.

Rogers DJ, Randolph SE, 2003. Studying the global distribution of infectious diseases using GIS and RS. Nat Rev Microbiol 1, 231-237.

Ross AGP, Sleigh AC, Li YS, Davis GM, Williams GM, Jiang Z, Feng Z, McManus DP, 2001. Schistosomiasis in the People's Republic of China: prospects and challenges for the 21st century. Clin Microbiol Rev 14, 270-295.

Spiegelhalter DJ, Best N, Charlin BP, van der Linde A, 2002. Bayesian measure of model complexity and fit. J R Stat Soc
Ser B-Stat Methodol 64, 583-639.

Steinmann P, Zhou XN, Li YL, Li HJ, Chen SR, Yang Z, Fan W, Jia TW, Li LH, Vounatsou P, Utzinger J, 2007. Helminth infections and risk factor analysis among residents in Eryuan county, Yunnan province, China. Acta Trop 104 (in press).

Utzinger J, Bergquist R, Xiao SH, Singer BH, Tanner M, 2003. Sustainable schistosomiasis control - the way forward. Lancet 362, 1932-1934.

Utzinger J, Zhou XN, Chen MG, Bergquist R, 2005. Conquering schistosomiasis in China: the long march. Acta Trop 96, 69-96.

Wang XH, Wu XH, Zhou XN, 2006. Bayesian estimation of community prevalences of Schistosoma japonicum infection in China. Int J Parasitol 36, 895-902.

Wu GL, 2002. A historical perspective on the immunodiagnosis of schistosomiasis in China. Acta Trop 82, 193-198.

Yang GJ, Vounatsou P, Zhou XN, Tanner M, Utzinger J, 2005a. A Bayesian-based approach for spatio-temporal modeling of county level prevalence of Schistosoma japonicum infection in Jiangsu province, China. Int J Parasitol 35, 155-162.

Yang GJ, Vounatsou P, Zhou XN, Tanner M, Utzinger J, 2005b. A potential impact of climate change and water resource development on the transmission of Schistosoma japonicum in China. Parassitologia 47, 127-134.

Yang GJ, Vounatsou P, Zhou XN, Utzinger J, Tanner M, 2005c. A review of geographic information system and remote sensing with applications to the epidemiology and control of schistosomiasis in China. Acta Trop 96, 117-129.

Yogore MG Jr, Lewert RM, Blas BL, 1983. Seroepidemiology of schistosomiasis japonica by ELISA in the Philippines. I. Underestimation by stool examination of the prevalence of infection in school children. Am J Trop Med Hyg 32, 1322-1334.

Yu JM, de Vlas SJ, Jiang QW, Gryseels B, 2007. Comparison of the Kato-Katz technique, hatching test and indirect hemagglutination assay (IHA) for the diagnosis of Schistosoma japonicum infection in China. Parasitol Int 56, 45-49.

Yu JM, de Vlas SJ, Yuan HC, Gryseels B, 1998. Variations in fecal Schistosoma japonicum egg counts. Am J Trop Med Hyg 59, 370-375. 
Zhou XN, Wang LY, Chen MG, Wu XH, Jiang QW, Chen XY, Zheng J, Utzinger J, 2005. The public health significance and control of schistosomiasis in China - then and now. Acta Trop 96, 97-105.

Zhou XN, Yang GJ, Yang K, Wang XH, Hong QB, Sun LP,
Malone JB, Kristensen TK, Bergquist NR, Utzinger J, 2007. Potential impact of climate change on schistosomiasis transmission in China. Am J Trop Med Hyg 77 (in press).

Zhu YC, 2005. Immunodiagnosis and its role in schistosomiasis control in China: a review. Acta Trop 96, 130-136. 